\title{
Consumer Preferences of Ratibida columnifera (Nutt.) Wooton \& Standl. Floral Characteristics
}

\author{
Kaitlin A. Hopkins, Charles R. Hall, and Michael A. Arnold \\ Department of Horticultural Sciences, Texas A\&M University, 2133 \\ TAMU, College Station, TX 77843-2133 \\ Marco A. Palma \\ Department of Agricultural Economics, Texas A\&M University, 2124 \\ TAMU, College Station, TX 77843-2124 \\ Melinda Knuth \\ North Carolina State University, Horticultural Science, 2721 Founders \\ Drive, Raleigh, NC 27607
}

\section{Brent Pemberton \\ Texas A\&M Agricultural Research and Extension Center, P.O. Box 200, Overton, $T X 75684$}

Additional index words. Asteraceae, conjoint analysis, native plant, part-worth utility, prairie coneflower, principal component analysis, wildflower

\begin{abstract}
Conjoint analysis can be used to simultaneously investigate consumer preferences on multiple attributes and levels. Our objective was to gain insight regarding consumer preferences for attributes and levels attributed to Ratibida columnifera, a wildflower of potential commercial interest. A ratings-based conjoint analysis using petal color (bicolor, marble, red, yellow), petal shape (circular, oval, notched, lobed), petal number (less than 10 , more than 10$)$, and price $(\$ 10.00, \$ 15.00, \$ 20.00)$ was conducted to elucidate part-worth utility from data from 1000 subjects recruited using Amazon Mechanical Turk (MTurk), a crowdsourcing marketplace. Subjects were then clustered according to their conjoint utility scores. In addition to the conjoint analysis, a principal component analysis was performed based on native plant knowledge of the respondent. Conjoint results revealed that petal color was the most important attribute in decision making, followed by price, petal shape, and petal number. Utility values revealed preference for bicolor petals, followed by red, yellow, and marbled color petals. Preference for price went from least expensive to most expensive. Circular petals were favored over oval, notched, and lobed. Subjects also preferred to have 10 petals or more, vs. less than 10 petals. Cluster analysis yielded three consumer segments, which differed in their utility values. These clusters differed in both demographics and $R$. columnifera preferences. Overall, consumers preferred $R$. columnifera with partial (bicolor) or complete red coloration over other options, lower prices, more petals, and entire circular or oval petals.
\end{abstract}

$R$. columnifera is a wildflower that exhibits a large variation in both floral and vegetative characteristics [U.S. Department of Agriculture (USDA), Natural Resources Conservation Service, 2018]. Consumers can currently purchase this plant via seeds, and occasionally as a potted plant; however, there are few cultivars or novel variations developed. Only a single cultivar, Red Midget, which is a shorter cultivar with an upright habit to $60 \mathrm{~cm}$ and red-brown disk flowers rimmed in orange and yellow, was found in the trade (Roots and Rhizomes, 2020). There are opportunities to introduce new variants of $R$. columnifera into the green industry trade. However, to ensure a successful commercialization of identified $R$. columnifera variants being developed, these new product introductions must resonate with potential consumers.
To that end, we tested the overall preferences for $R$. columnifera flowers by performing a conjoint analysis using selected key product traits. These novel floral traits were observed from specimen collections ranging from south Texas, to as far north as Nebraska by this research cohort. Knowledge concerning which of these novel traits is most preferred by consumers will help plant breeders reduce the risk of producing a product that does not resonate well with consumers. From the extensive literature using conjoint methods, we know that consumers typically base their purchasing decisions on simultaneous evaluation of several product characteristics, as opposed to just one characteristic (Behe et al., 1999). Conjoint analysis allows for isolation of a number of factors and can be used to determine importance of each factor (Behe et al., 1999). Conjoint analysis involves evaluative rankings or multiattribute alternatives by individuals (Baidu-Forson et al., 1997). This allows for measurement of consumer preferences among items with multiple attributes (Baidu-Forson et al., 1997). In addition, analyzing conjoint designs using TRANSREG is the standard set by Kuhfeld (2010). This model is commonly used to analyze conjoint design in SAS (SAS, Inc., Cary, NC). Analysis of responses to the conjoint analysis will reveal which floral traits are important to consumers based on their part-worth utility values. Consumer preference for selected traits could aid in future selections of germplasm candidates for commercialization. Considering that $R$. columnifera is a native plant to a large portion of North America, it also would be useful to be able to gauge a participant's knowledge of native plants as part of the data collection.

According to the 2017 Census of Agriculture, floriculture crops accounted for $\$ 3.8$ billion in sales. This category includes annuals, herbaceous perennials, vegetable plants, and hanging baskets. The USDA National Agricultural Statistics Service Floriculture crops summary stated that the wholesale value of all bedding and garden plants for 2020 amounted to \$2.01 billion [USDA National Agricultural Statistics Service (NASS), 2021]. This plant category was the largest contributor to total value sales of 2019 for floriculture crops. Potted herbaceous perennials totaled \$600 million in 2019 and accounted for 30\% of the total bedding and garden category (USDA NASS, 2020). $R$. columnifera is a wildflower in the family Asteraceae Bercht. \& J. Presl (Compositae), similar to Rudbeckia L. (coneflowers). Rudbeckia was sold as a potted herbaceous perennial plant and accumulated total sales of $\$ 10,234,000$ in the 2019 USDA Census of Agriculture. Rudbeckia, a wildflower when present in nature, now has cultivars that are commercialized and are likely the cause of these large sales. This is a similar path that we strive to take with development of $R$. columnifera. Increasing the number of variations available in both seed and potted forms, $R$. columnifera could increase in value as a commercial product. Both $R$. columnifera and Rudbeckia are native plants, which potentially gives them additional unique value to consumers.

Native plants make up $\approx 9.1 \%$ of total sales of the nursery industry in the United States (Khachatryan et al., 2020). Through surveys conducted of nursery retailers, landscape architects, and Master Gardeners, three general factors were considered important: 1) the availability of native plants; 2) consumer preferences regarding ornamental qualities in comparison with exotic species; and 3 ) knowledge about native plants (Wilde et al., 2015). Increasing availability would be best accomplished through existing supply chains that are currently primarily supplying exotics (Wilde et al., 2015). Another study showed that the main reason surveyed nurseries supplied native plants was client request $(21.7 \%)$, followed by low maintenance $(17.8 \%)$, ecological reasons $(16.3 \%)$, and that native plants are best adapted to difficult planting sites 
(15.5\%) (Brzuszek and Harkess, 2009). From the same study, nurseries listed that their main reason for not selling more native plants was because of not enough customer interest (36.4\%) and unfamiliarity with natives (20.2\%) (Brzuszek and Harkess, 2009).

Native plants need to meet the same consumer preferences regarding ornamental qualities when competing with exotic alternatives in the marketplace (Wilde et al., 2015). Aesthetic qualities of native plants can vary widely (Zadegan et al., 2008). Many native plant species have a tendency to grow in groups or colonies rather than single species stands and often produce small flowers with short bloom periods (Zadegan et al., 2008). Although native plants can be more expensive than exotic plants, price has been one of the least important factors limiting consumer acceptance (Wilde et al., 2015). It was determined in their conjoint choice survey that consumers would pay more for well-designed landscapes that included native plants rather than lawns. Another insight from their study was that consumers were willing to pay more for plants labeled as noninvasive and native. Based on this finding, environmental traits of native ornamentals could be considered valueadded traits. In the same study, half of consumers purchased ornamentals based on plant traits, not origin or invasive potential (Wilde et al., 2015).

Consumers are also willing to pay more for alternative designs that incorporate any form of prairie garden compared with a conventional lawn (Helfand et al., 2006). It has been noted, that due to the hypothetical bias of survey-based methods, willingness to pay elicited from hypothetical decision tasks almost always exceeds willingness to pay elicited from nonhypothetical decision tasks (Chang et al., 2009). In a survey of Florida native plant producers, Kauth and Pérez (2011) indicated that lack of desired species was the biggest limitation to the Florida native wildflower market. Other limiting factors identified in this survey included

Received for publication 3 Sept. 2021. Accepted for publication 16 Nov. 2021.

Published online 1 February 2022.

This study was supported in part by funds from Texas A\&M AgriLife Research and the U.S. Department of Agriculture National Institute of Food and Agriculture. Mention of a trademark, proprietary product, or vendor does not constitute a guarantee or warranty of the product by the authors, Texas A\&M University, or Texas A\&M AgriLife Research and does not imply its approval to the exclusion of other products or vendors that also may be suitable.

K.A.H. is a Graduate Student.

C.R.H. is a Professor and Ellison Chair.

M.A.A. is a Professor and Director of The Gardens at TAMU.

M.A.P. is a Professor.

M.K. is a Professor and Regents Fellow.

K.A.H. is the corresponding author. E-mail: kah147@shsu.edu.

This is an open access article distributed under the CC BY-NC-ND license (https://creativecommons. org/licenses/by-nc-nd/4.0/). education of customers and industry, accuracy of labeling, reliability of seed sources, need for new market development, and the availability of desired species (Kauth and Pérez, 2011).

In a study focusing on landscape architects' use of native plants, residential projects ranked highest in use $(30 \%)$, followed by commercial $(25.1 \%)$, municipal $(16.1 \%)$, and finally federal projects $(8.5 \%)$ (Brzuszek et al., 2007). When these same landscape architects were asked why native plants were selected, they indicated that natives were best adapted to the site conditions (31.2\%) (Brzuszek et al., 2007). Less than $20 \%$ of these respondents claimed to plant native plants at the request of clients, which could indicate that landscape architects are selecting native plants independently from client demand (Brzuszek et al., 2007).

A better understanding of consumers' preferences for native plants, their attitudes toward bringing a more naturalistic design into the built environment, and purchasing behavior is needed to better characterize the market for producers of native plants and other horticultural professionals (Zadegan et al., 2008). Nevada survey respondents rated the importance of four major benefits of native species, the most important being drought resistance, with $75.8 \%$ of respondents (Curtis and Cowee, 2007). The next most important trait of a native plant to Nevada respondents was the natural appearance of the plant (60.2\% rating) (Curtis and Cowee, 2007). The third most important characteristic was protection from invasive plant species post wildfire $(40.8 \%)$, followed by erosion control (22.7\%) (Curtis and Cowee, 2007). Traits that are popular with consumers include extended flowering, novel floral morphology, compactness, and disease resistance (Wilde et al., 2015). Further development of native ornamentals with improved flowering, architecture, and drought-tolerance traits may be a strategy to increase native plant use among a large segment of the consumer market (Wilde et al., 2015).

Native plants attract native insects and birds to a greater percentage than areas without native plants (Burghardt et al., 2009). There is also evidence that the presence of non-native plants can reduce native lepidopteran (order Lepidoptera L.) insect species (Burghardt et al., 2010). In addition to lepidopteran visitations, native plants are also preferred by 23 bee species as opposed to non-native plants that were visited by only one bee species (Morandin and Kremen, 2013). They also found more native bee species on native plants (Morandin and Kremen, 2013). In mature hedgerow sites where native floral cover was similar to exotic floral cover, they found that native bees, and in some instances honeybees, preferred native plants (Morandin and Kremen, 2013). They suggested that creation of native plant hedgerows in intense agricultural areas may benefit honeybee colony health (Morandin and Kremen, 2013).
Conjoint analysis has been used to identify consumer segments based on their preferences for green industry products (Behe et al., 2014). These analyses allow us to understand the effects of product attributes as well as the influence of demographics on choice decisions (Behe et al., 2014). Conjoint analysis on landscape plant material revealed that landscapes with annual and perennial color increased the perceived value of homes (Behe et al., 2005). Color differences have shown to be very important factors in purchasing decision making (Behe et al., 1999). In a separate study that investigated local and sustainable plant production characteristics, plant type was seen as important (Behe et al., 2013). Price also can be a major contributing factor for consumers in making decisions to purchase a product (Mason et al., 2008). By performing conjoint analysis on attributes of $R$. columnifera, we may be able to develop it into a value-added product that will better resonate with potential customers.

\section{Materials and Methods}

The online survey consisted of four sections: 1) eliciting recent plant purchasing behaviors, 2) determining existing native plant knowledge and preferences, 3) the $R$. columnifera conjoint analysis, and 4) demographic characteristics of the respondents. The conjoint design used for this study included a combination of categorical plant and product attributes and levels that represented four flower colors, four petal shapes, two petal numbers, and three price levels per container (Table 1) that align with common price points gathered from big box stores, online sales, and garden centers for similar products for a $4 \times 4 \times 3 \times 2$ factorial design (Knuth et al., 2018). Attributes and levels pertaining to $R$. columnifera floral characteristics were based off of variation found in nature. The four flower colors were red, yellow, bicolor, and marble. Petal shapes included oval, lobed, notched, and circular. The two petal number levels were less than 10 and more than 10 . The three price levels were $\$ 10.00, \$ 15.00$, and $\$ 20.00$, which were chosen based on current market sales price data for trade 1-gallon $(\approx 3 \mathrm{~L}) R$. columnifera containers. This resulted in 96 hypothetical combinations, or profiles, which was too numerous to eliminate the possibility of subject fatigue. Thus, \%mktruns macro in SAS (version 25) was used to select 16 of these combinations to be used in the consumer questionnaire, which is few enough combinations to reduce subject fatigue and time investment of the respondent (Knuth et al., 2018). This gave the efficiencies of each possible design size, and 16 combinations were chosen for our design because it was the saturated design size.

The conjoint analysis will aid in assessing a consumer's preference on each product attribute, meaning we can determine levels of partworth utility associated with each attribute and the product as a whole (Knuth et al., 2018). The survey used digital images consisting of a 
Table 1. Attributes, levels, and images within the conjoint analysis of floral characteristics and price for container grown Ratibida columnifera used to elucidate preferences of survey respondents.

Attributes

Flower color

Petal number

Less than 10

More than 10

$\$ 10.00$
Price
$\$ 15.00$

$\begin{array}{rr} & \$ 10.00 \\ & \$ 15.00\end{array}$

$\begin{array}{ll}\text { Price } & \$ 10.00 \\ & \$ 15.00\end{array}$

$\$ 20.00$

Bicolor

Marble

Red

Yellow

Circular

Notched

Lobed

Oval
Petal shape
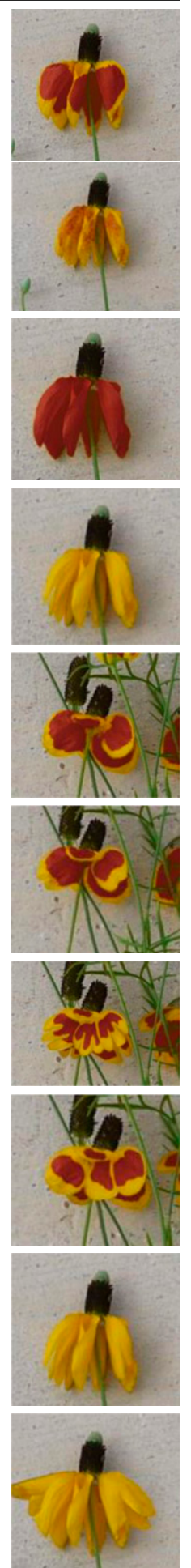

Likert scale of 0 (very unlikely) to 5 (very likely) (Wollaeger et al., 2015).

Conjoint images consisted of a description of attributes above the image of the plant with the Likert scale below the image (Fig. 1). This conjoint design will provide knowledge of consumers' part-worth utility values, which is valuable information when it comes to marketing strategy, pricing decisions, and new product development (Breidert et al., 2006). In conjoint experiments, participants rate different products to estimate a preference from which part-worth utility can be derived (Breidert et al., 2006).

The survey also solicited information regarding native plant use in landscapes as well as gauging respondent knowledge on other native plant topics. Last, demographic questions such as number of adults in household, children in household, age, gender, ethnicity, education level, area of residence/ developed environment, and income were asked (Wollaeger et al., 2015). The survey was developed and administered in Qualtrics (Provo, UT) (Wollaeger et al., 2015) and was active until survey completion (number of needed responses achieved).

Potential survey respondents were contacted from a pool maintained by MTurk and invited to participate in the survey (Wollaeger et al., 2015). Participants were restricted based on geographic area, as they needed to be residents of the United States because $R$. columnifera is to be marketed in that location. A recent study analyzed the demographics and dynamics of Amazon Mechanical Turk participants (referred to as workers), which revealed some differences between the worker population and actual population

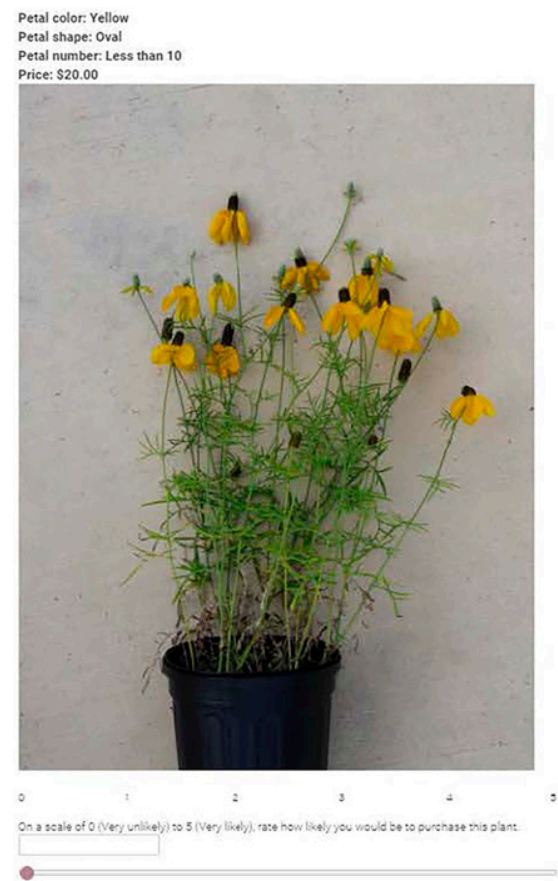

photo of the plant in a container photographed against a neutral background with the accompanying price and characteristics listed above the image (Knuth et al., 2018). The analysis included use of a balanced Likert scale to allow respondents to rate the likelihood of purchase for each profile (Wollaeger et al., 2015). An example of a likelihood to purchase question would show the profile and then ask the consumer "How likely would you be to purchase this plant?" The respondent would then have the ability to respond with a whole unit on the
Fig. 1. An example screenshot of one conjoint image shown to 1000 subjects in an online consumer preference survey pertaining to Ratibida columnifera plant attributes and native plants. 
(Difallah et al., 2018). In their study, the workforce gender was balanced, although the age tended to be younger than the overall population. It was also found that MTurk workers have household incomes that were slightly below the average US population (Difallah et al., 2018). By asking demographics questions within our survey, we will be better able to claim whether choices made in our study might reflect that of the population as a whole. Both the survey development and methodology of data collection were approved by the university committee involving research with human subjects (Texas A\&M University IRB\# 2018-1655M Exempt AC 3YR).

Conjoint analysis identified relative importance for main attributes and part-worth values for each level of the attributes that were then used to segregate the sample into clusters based on part-worth utilities using SAS software (version 25) PROC CLUSTER. Relative importance is defined as a measure of importance of the contribution of each attribute to overall preference, and is calculated by dividing the range of utilities for each attribute by the sum of all ranges and multiplying by 100 (Kuhfeld, 2010). Principal component analysis describes the strength and direction of correlated variables in terms of their potential to quantify unobservable constructs (Knuth et al., 2020). Principal component analysis was performed using SAS and retained 10 items of 19 possible items due to their factor loadings being $\geq 0.500$ (Knuth et al., 2020). This solution was unrotated. These 10 items were also chosen based on leveling off of eigenvalues in the scree plot. The chosen eigenvalue for one component was 44.678. Kaiser-Meyer-Olkin measure was 0.875 , and Bartlett's test of sphericity $\chi^{2}$ was 3974.252 . The loading value is used in principal component analysis to indicate the mean value for each item (question), being highest among all of the mean values for that item when testing for linear combinations (Knuth et al., 2020). Statistical analysis used in this study was as follows: principal component analysis on native plant questionnaire using IBM SPSS Statistics 25 (IBM SPSS Statistics for Windows, Version 25.0. IBM Corp., Armonk, NY), conjoint analysis using TRANSREG and FASTCLUS in SAS (version 25), and distribution analysis, $\chi^{2}$, and F-test of data in JMP Pro 15 (SAS Institute Inc., 1989-2021).

\section{Results and Discussion}

The survey was administered to 1384 potential participants. Subjects who agreed with the consent form and passed the survey check (where subjects were directed to answer in a specific way to ensure subjects were reading every question carefully) totaled 1000.

The mean age of respondents was 38.2 years ( \pm 10.4 years), and respondents were predominantly male $(60 \%$, Table 2$)$. Respondents were primarily white $(56 \%)$, followed by Asian (34\%), African American (5\%), Hispanic $(3 \%)$, Native American (1\%), Other $(1 \%)$, Prefer not to respond (1\%), and Pacific Islander $(0 \%)$. More than half of respondents had a 4-year degree (54\%), followed by some college (14\%) and master's degrees (14\%). Respondents mainly resided in suburban regions $(40 \%)$, followed by metropolitan regions (32\%), with the remaining living in rural areas $(28 \%)$. Mean yearly income for respondents was $\$ 52,370( \pm \$ 37,157)$.

Demographic characteristic comparison. In this study, respondents were $60 \%$ male, which is much higher than the $49.2 \%$ male population of the United States in 2019 reported by the U.S. Census Bureau (2020). Median age of subjects in this study (38.2 years) was very close to the median age of the United States (38.5 years) (U.S. Census Bureau, 2020). Our subject sample had a greater proportion of people of color when compared with the U.S. Census Bureau, which had 72\% White, $12.8 \%$ African American, 0.9\% American Indian and Alaska Native, $5.7 \%$ Asian, $0.2 \%$ Native Hawaiian and other Pacific Islander, 5\% other, and $3.4 \%$ with two or more races. Individuals of Hispanic backgrounds make up $18.4 \%$ of the population. In particular, our study had a high number of Asian participants (34\%) (U.S. Census Bureau, 2020). The 2019 U.S. Census had $88.6 \%$ who had attained a high school education or higher, whereas $100 \%$ of our subject sample had education of high school or higher

Table 2. F-test and $\chi^{2}$ comparison of percentages and values of demographic characteristics of respondents, by overall sample and by clusters, that participated in a survey involving conjoint analysis of floral characteristics and price of Ratibida columnifera. ${ }^{\mathrm{z}}$

\begin{tabular}{|c|c|c|c|c|c|c|}
\hline \multicolumn{2}{|c|}{ Demographic variables } & \multicolumn{4}{|c|}{ Mean $(\mathrm{SD})$ or $\%$} & \multirow[b]{2}{*}{ Statistic, $P$ value } \\
\hline$(\mathrm{Ca}$ & rical) & $\frac{\text { Total sample }}{\mathrm{N}=1000}$ & $\begin{array}{c}\begin{array}{c}\text { Single color oval } \\
\text { petal lovers }\end{array} \\
\mathrm{n}=181 \\
\end{array}$ & $\begin{array}{c}\begin{array}{c}\text { Price conscious } \\
\text { bicolor petal lovers }\end{array} \\
\mathrm{n}=418\end{array}$ & $\begin{array}{c}\begin{array}{c}\text { Knowledgeable } \\
\text { marbled petal } \\
\text { lovers }\end{array} \\
\mathrm{n}=353 \\
\end{array}$ & \\
\hline \multirow{2}{*}{$\begin{array}{l}\text { Gender }(M=1 ; \\
\quad F=2)\end{array}$} & Male & 60 & 60 & 61 & 60 & $\chi^{2}=0.018,0.9910$ \\
\hline & Female & 40 & 40 & 39 & 40 & \\
\hline \multirow{6}{*}{ Ethnicity } & Hispanic & 3 & 1 & 4 & 3 & \\
\hline & Native American & 1 & 1 & 1 & 1 & \\
\hline & Pacific Islander & 0 & 0 & 0 & 0 & \\
\hline & White/Caucasian & 56 & 50 & 62 & 47 & \\
\hline & Other & 1 & 1 & 2 & 1 & \\
\hline & $\begin{array}{l}\text { Prefer not to } \\
\text { respond }\end{array}$ & 1 & 1 & 1 & 0 & \\
\hline \multirow{4}{*}{ Education } & $\begin{array}{l}\text { 4-year college } \\
\text { degree }\end{array}$ & 54 & 58 & 52 & 56 & \\
\hline & Master's degree & 14 & 14 & 11 & 17 & \\
\hline & $\begin{array}{l}\text { Professional degree } \\
\quad(\mathrm{JD}, \mathrm{MD})\end{array}$ & 1 & 1 & 1 & 1 & \\
\hline & Doctoral degree & 0 & 0 & 0 & 1 & \\
\hline \multirow[t]{3}{*}{ Area of residence } & Metropolitan region & 32 & 29 & 33 & 33 & $\mathrm{~F}=5.183,0.0058$ \\
\hline & Rural region & 28 & 25 & 21 & 39 & \\
\hline & Suburban region & 40 & 45 & 46 & 29 & \\
\hline Age (yrs) & & $38.2( \pm 10.4)$ & $36.7( \pm 9.6)$ & $39.4( \pm 10.9)$ & $36.8( \pm 9.5)$ & \\
\hline \multicolumn{2}{|c|}{ Yearly income (USD \$, 000) } & $52.3( \pm 37.2)$ & $56.2( \pm 39.1)$ & $52.5( \pm 35.6)$ & $51.1( \pm 38.4)$ & $\mathrm{F}=1.155,0.3155$ \\
\hline
\end{tabular}

${ }^{\mathrm{z}}$ Data analyses were generated across the rows using $\chi^{2}$ and F-test in JMP Pro 15 software (SAS Institute Inc., Cary, NC, 1989-2021). 
(U.S. Census Bureau, 2020). The U.S. Census had $33.1 \%$ with education of a 4-year degree or higher, and our study had 69\%, showing that our subject sample was more highly educated (U.S. Census Bureau, 2020). In 2019, the median earnings were $\$ 43,215$, and our study had an overall median income of $\$ 52,370$ (U.S. Census Bureau, 2020). Readers should be careful to make generalizations from this study to the overall population because respondent demographics do not exactly match census data.

Using Proc FASTCLUS, which divides the observations into clusters such that each observation belongs to one and only one cluster using Euclidean distances (the cluster centers that are based on least squares estimations). Three clusters emerged from the data set based on the convergence.

Cluster 1 had the youngest group (36.7 years) and cluster 2 had the oldest (39.4 years). Yearly income overall was $\$ 52,370$ $(\mathrm{SD}=\$ 37,157)$. Cluster 1 had the highest income of $\$ 56,243.09$ ( $\mathrm{SD}=\$ 39,132.63)$, followed by cluster 2 of $\$ 52,488.04$ (SD = $\$ 35,624.35)$ and cluster 3 with $\$ 51,076.49$ $(\mathrm{SD}=\$ 38,375.79)($ Table 2).

Recent plant purchasing behavior was quantified using a five-question purchasing pattern survey (Table 3 ). In the total sample $(\mathrm{N}=1000), 41 \%$ of participants stated that they spent $\$ 1$ to $\$ 100$ on plants and gardening supplies in the past 6 months, with the next highest expenditure being \$101 to \$200 at $29 \%$. All clusters had the most participants indicating expenditure of $\$ 1$ to $\$ 100$ in the past 6 months. When asked what percent of yearly plant purchases were locally produced, $23 \%$ of participants spent $26 \%$ to $50 \%$ on locally produced products. Cluster 1 indicated expenditure of $26 \%$ to $50 \%$ on locally produced products. Cluster 2 had $21 \%$ indicate spending only $1 \%$ to $25 \%$ on locally produced goods, and also had the highest percentage of participants who did not know if the source was local or not $(21 \%)$. Participants in cluster 3 purchased locally sourced plants the most, with $53 \%$ of participants spending $26 \%$ to $75 \%$ on locally sourced plants. Independent, free-standing garden centers and home improvement stores were mainly frequented by our participants, comprising $49 \%$ of participant purchases over the past 6 months. Participants purchased 28\% from supermarkets and grocery stores. Participants also used Internet sales (28\%), which outcompeted mass merchandisers and print catalogs. Participants purchased most of their plant and gardening supplies from independent free-standing garden centers $(39 \%)$ and home improvement stores (32\%). Cluster 1 frequented garden centers and home improvement stores equally $(48 \%, 48 \%)$, and closely aligned with the total sample with regard to distribution of locales. Cluster 2 had more purchases from home improvement stores $(58 \%)$ and garden centers $(56 \%)$, and had the least amount of Internet sales of all clusters $(16 \%)$. Cluster 3 purchased more plants from grocery stores (33\%), the Internet $(25 \%)$, and mass merchandisers $(16 \%)$ than other clusters. Impacts of coronavirus disease
2019 restrictions on purchasing sources for this study are unknown, but could conceivably have enhanced online purchases relative to brick-and-mortar outlets.

Vegetable plants (53\%), annual flowering plants $(40 \%)$, and herbs $(36 \%)$ were the main types of plants that were purchased overall by participants, followed closely by flowering perennials $(32 \%)$ and indoor flowering potted plants $(30 \%)$. Cluster 1 and cluster 3 purchased plants similarly to the total sample. Cluster 2 purchased more herbs $(40 \%)$, perennials $(35 \%)$, and indoor flowering potted plants $(39 \%)$ than the total sample.

Conjoint findings. A conjoint design is interpreted by evaluating a set of features, or attributes, of a product. Each of these attributes has a level of importance quantified, and therefore placed in order of greatest importance (largest positive number) to least importance (smallest number, or negative number). In addition, within each attribute can be levels that also can be ordered by their part-worth utility in the purchase decision following the same framework as the relative importance of the overall attribute. Table 4 reports the relative importance of the overall attributes being tested, with the second portion of the table reporting the part-worth utility values of each level of each attribute. Overall, petal color was the most important attribute of the four that were tested. This was followed by price, petal shape, and petal number (Table 4). Within petal color, bicolor was preferred over red, yellow, and marble, respectively. Levels for the price attribute went from least expensive to most expensive in order of preference. The most preferred petals shape overall was circular, followed by oval, notched, then lobed. More than 10 petals were preferred over less than 10 petals for the petal number attribute.

There were some differences among the clusters with regard to preference. All clusters ranked petal color as most important; however, cluster 2 was more price conscious than the other two clusters. Cluster 1 was least conscious of price among the clusters. Cluster 3 had a slightly higher preference for color shape than other clusters.

Utility scores had differences among clusters. Cluster 1 is unique in the preference of red flower color, whereas the other clusters mainly preferred bicolor. Cluster 3 least preferred the red-colored petals, whereas cluster 1 and cluster 2 least preferred the marble coloration. Cluster 3 would pay more $(\$ 15.00)$ than the other two clusters.

Principal component analyses. The principal component analyses of 10 questions on native plant knowledge (Table 5) yielded one component. It was labeled Native Knowledge (Table 6). When comparing mean scores for the component across clusters, cluster 3 had the higher native plant knowledge mean, followed by cluster 1 and then cluster 2 .

Conjoint clusters. Three clusters formed from the cluster analysis, which were then compared. Comparisons were made across the clusters using analysis of variance of the demographic characteristics, including age, gender, ethnicity, education, area of residence, income, native plant knowledge, number of purchase locations, and number of plant types purchased within the past 6 months (Table 7).

Among the three clusters that emerged, gender, income, and number of purchase locations did not vary. Cluster 1 had young participants and intermediate education, nonWhite participants, native plant knowledge, and number of plant types purchased. Cluster 1 participants mainly resided in suburban regions. They had intermediate petal number preference in comparison with the other clusters. They preferred red or yellow flowers more so than the other clusters and had intermediate preference for marble coloration. They least preferred bicolor flower color the most out of all clusters. Oval and circular petal shapes were preferred the most by this cluster, with intermediate preferences toward notched and lobed shapes. This cluster shows preference for the $\$ 10.00$ price point, and was less likely to spend $\$ 15.00$ or $\$ 20.00$, according to utility values. Given these characteristics, cluster 1 was labeled as "Single color oval petal lovers" (Table 7).

Cluster 2 had the highest mean age average at 39.4 years. This cluster also had the highest percentage of non-White participants, resided mainly in suburban areas, and had the least educated participants of the three clusters. Cluster 2 also had the lowest native plant knowledge of the three clusters. However, this cluster did purchase a larger variety of plant types than the other clusters. They had strong preference for petal number, having the least preference for less than 10 petals, and a greater preference for more than 10 petals when compared with other clusters. They stood out among clusters in their strong preference for bicolor petal color and aligned with cluster 1 in their preference for red petal color. They disliked marble and yellow petal colors the most when compared with other clusters. Petal shape preferences for this cluster aligned with other clusters except for their strong dislike for the lobed petal shape. This cluster preferred the lowest price possible $(\$ 10.00)$ and least preferred the highest price (\$20.00). Because of this, we labeled this cluster as "Price conscious bicolor petal lovers" (Table 7).

Cluster 3 was intermediate in age and non-White participants. This cluster had high education when compared with the "price conscious" cluster. Cluster 3 had more rural participants, had the most plant knowledge, and purchased the fewest types of plants of the three clusters. Cluster 3 differed from the others in their preference for less than 10 petals, and least preferred 10 petals or more. Cluster 3 preferred marble coloration the most of the three clusters. Cluster 3 was intermediate in preference for the other petal color levels. Cluster 3, which preferred oval and lobed petal shapes, was intermediate in preference for notched petal shape, and least preferred circular petal shape. Cluster 3 least preferred the lowest price $(\$ 10.00)$ and had the most interest in paying higher prices $(\$ 15.00, \$ 20.00)$, so we labeled this cluster 
Table 3. Chi-square comparison of percentage of plant supplies and product purchases by respondents in the past 6 months to a plant purchasing patterns survey for overall sample and by cluster. ${ }^{z}$

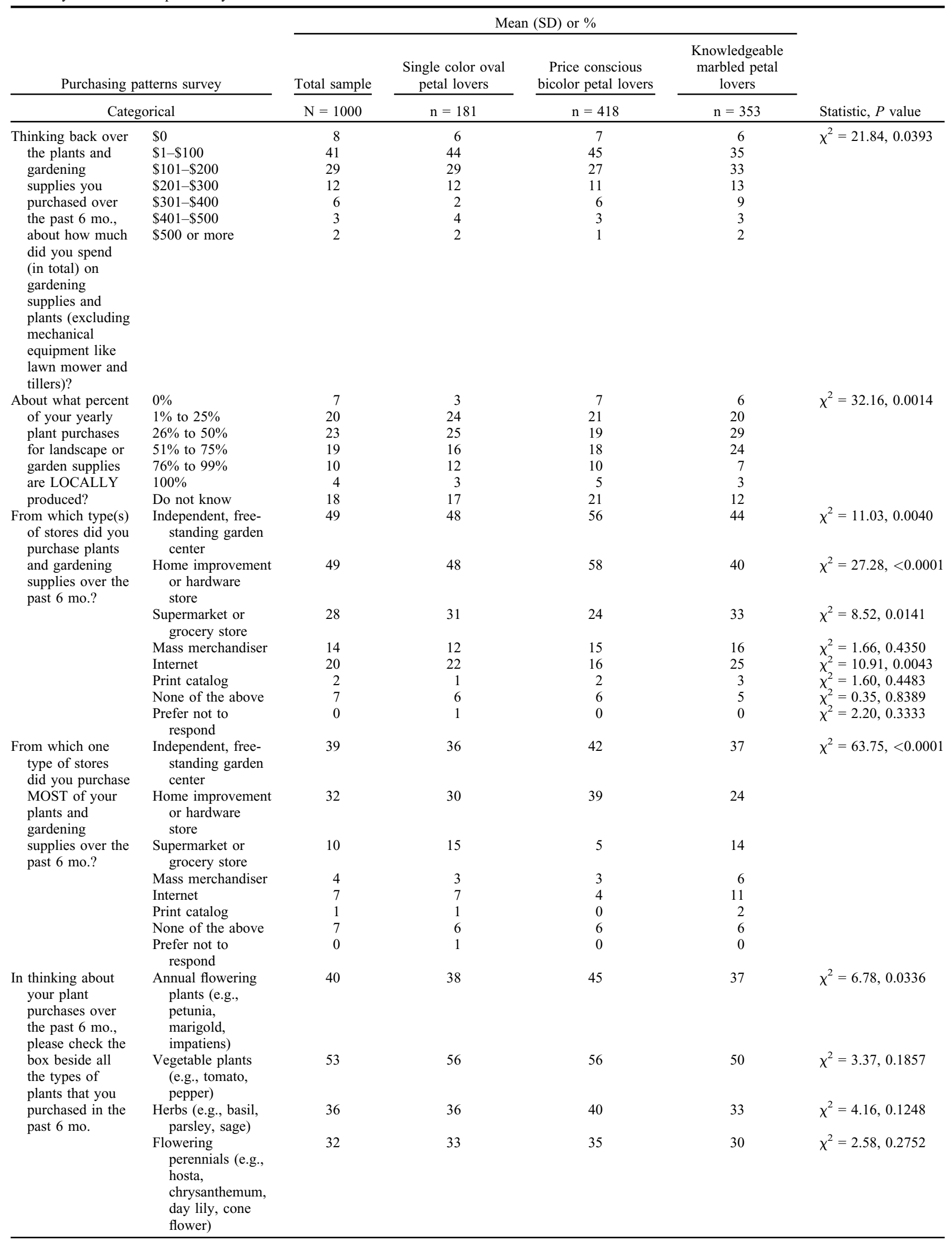




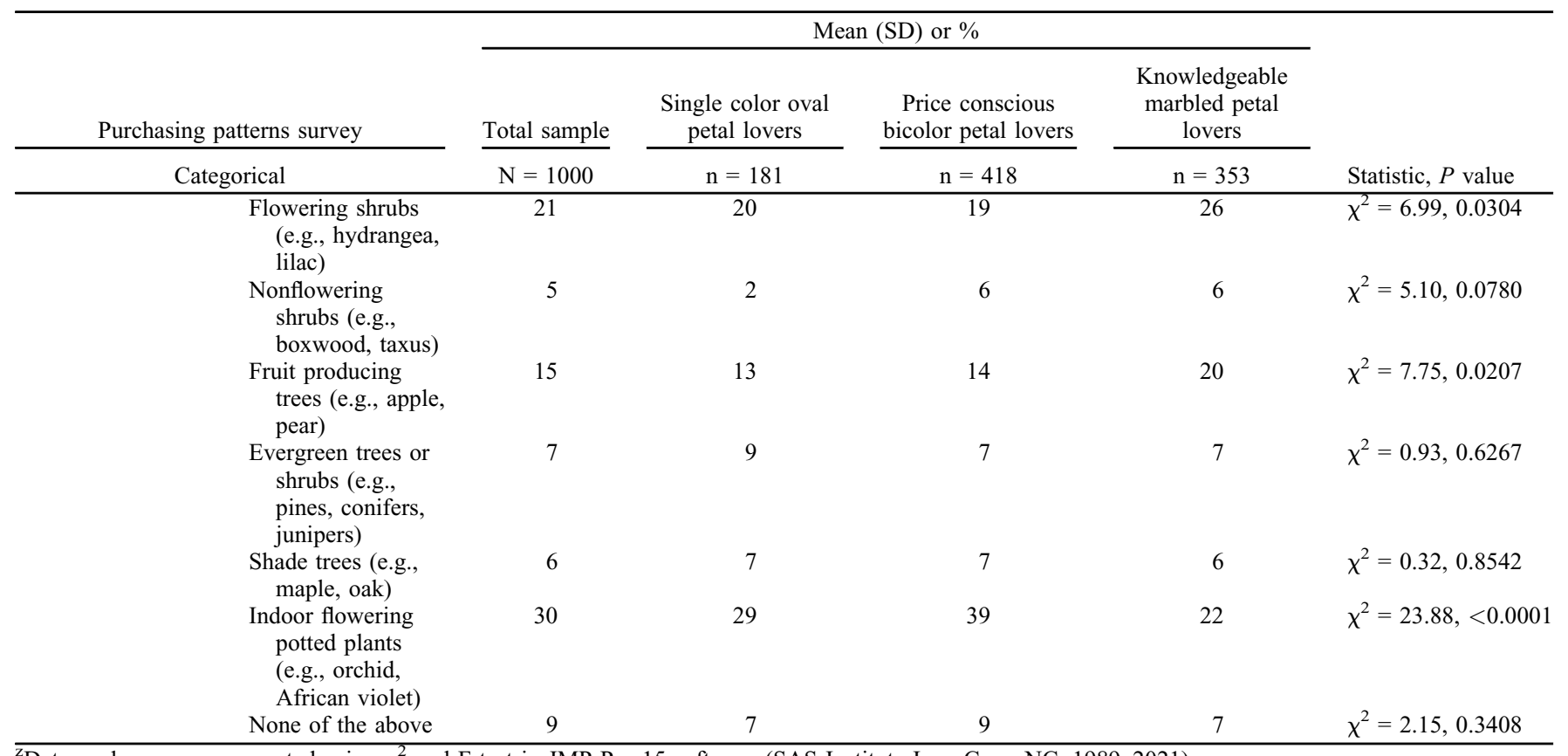

${ }^{\mathrm{z}}$ Data analyses were generated using $\chi^{2}$ and F-test in JMP Pro 15 software (SAS Institute Inc., Cary, NC, 1989-2021).

as "Knowledgeable marbled petal lovers" (Table 7).

Conjoint findings and previous literature. The conjoint study findings were consistent with prior research with regard to the importance of flower color and price (Behe et al., 1999; Mason et al., 2008). Overall, petal color was the most important attribute, followed by price, petal shape, and petal number. Petal color and price being the most important factors is a reoccurring theme in conjoint analysis results (Behe et al., 2001). Petal number is commonly the least important attribute in conjoint analyses where it is included (Grygorczyk et al., 2016). In roses, subjects preferred full-petaled roses, as opposed to single semidouble petals and double petals (Grygorczyk et al., 2016). Because of the results of the conjoint analysis, improvements of $R$. columnifera with regard to petal color would prove to be the most valuable from a consumer purchasing standpoint. Utility values give more insight into which colors are more desirable.

Part-worth conjoint utility values. Bicolor petals were preferred over other petal color levels overall according to the part-worth utility values. A preference for two-toned petals was also observed with a conjoint survey performed on roses (Rosa L.) (Grygorczyk et al., 2016) and impatiens (Impatiens hawkeri W. Bull) (Berghage and Wolnick, 2000). After bicolor, the colors in order from most preferred to least preferred in the overall sample were red, yellow, and, finally, marble. Red is a popular preference for many floral products like roses (Grygorczyk et al., 2016), geraniums (Pelargonium $\times$ hortorum L.H. Bail.) (Behe et al., 1999), impatiens (Berghage and Wolnick, 2000), and poinsettias (Euphorbia pulcherrima Willd. ex Klotzsch) (Behe et al., 1997). Because the

Table 4. Means and standard errors (SEs) for conjoint analysis levels and attributes showing mean relative importance scores and SEs for each attribute overall and by cluster derived from responses by participants to a conjoint analysis of floral characteristics and price of Ratibida columnifera. ${ }^{\mathrm{Z}}$

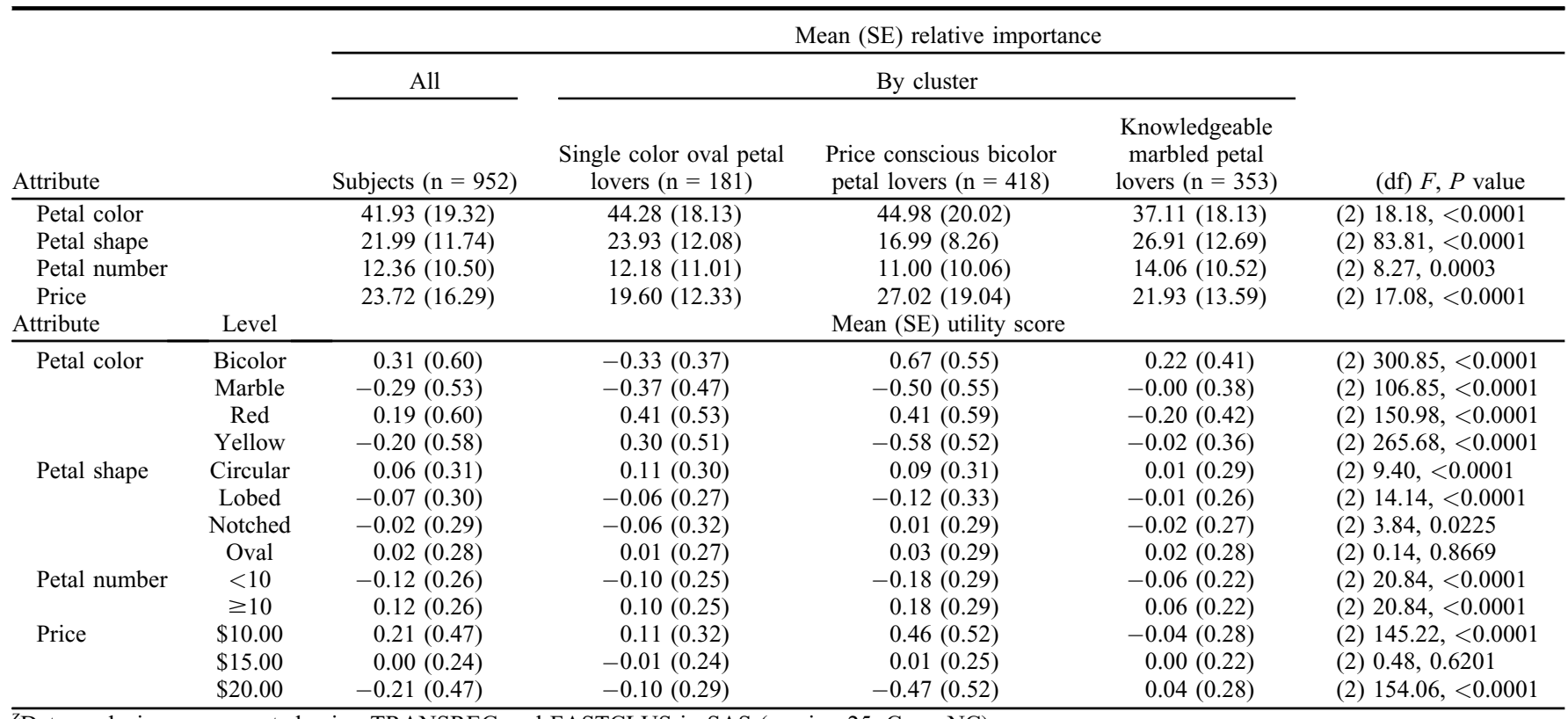

${ }^{\mathrm{z}}$ Data analysis was generated using TRANSREG and FASTCLUS in SAS (version 25, Cary, NC). 
Table 5. Principal component analysis component matrix for native knowledge questionnaire used to determine native knowledge value of respondents participating in a survey to elucidate consumer preference of floral characteristics and price for Ratibida columnifera.

Questions Component 1

I consider myself knowledgeable about native plants. 0.841

I keep current on the most recent developments in native perennial plants.

I can recognize plants native to my area.

I can recall many plants native to my area from memory.

Dense and compact landscape plants are important to me.

I know where to purchase plants native to my area.

I am interested in perennial native plants.

Work should be done to develop new native plant selections.

Longer blooming seasons are important to me.

Ratibida columnifera (Mexican Hat Wildflower) would be attractive in a cut flower arrangement.

Eigenvalue

Kaiser-Meyer-Olkin measure of sampling adequacy

Bartlett's test of sphericity

0.781

0.781

0.775

0.653

0.632

0.563

0.529

0.509

0.507

44.678

0.875

3974.252

bicolor $R$. columnifera is the wild-type coloration that is readily available, it could be profitable to develop a solid red $R$. columnifera seeing as that is the color that is preferred across many species. Price preference followed what would logically be expected, the lowest price, $\$ 10.00$, was most preferred, followed by
$\$ 15.00$ and $\$ 20.00$, respectively. When it comes to floral products, it is a common theme to have lower prices preferred to higher prices (Behe et al., 1999). Overall, a circular petal shape was preferred over all other shapes (oval, notched, lobed). There is little to be found in the literature regarding consumer preference of petal shapes. Subjects preferred inflorescences with more than 10 petals, as opposed to one with less than 10 petals. This is the opposite reaction from that of the rose study from Grygorczyk et al. (2016), in which double-petaled roses were least preferred by the participants.

When looking at the data for the entire sample, preferences of our subjects were largely consistent with findings of conjoint analyses in the previous literature (Grygorczyk et al., 2016; Behe et al., 1999). Consumers preferred $R$. columnifera with partial (bicolor) or complete red coloration over other options, lower prices, more petals, and entire circular or oval petals.

Conjoint clusters. The price conscious bicolor petal lovers fall into the age range of the Gen X generation (individuals born between 1965 and 1980), as opposed to the single color oval petal lovers and the knowledgeable marbled petal lovers who are both in the Gen Y population (individuals born between 1981 and 1995) (Behe et al., 2016; Knuth et al., 2020). This group is the most price conscious, having the greatest preference for lower prices and greatest aversion to higher prices. This cluster had the least formal education, and the least

Table 6. F-test comparison of mean and SD of the principal components by cluster for native knowledge questionnaire used to determine native knowledge value of respondents participating in a survey to elucidate consumer preference of floral characteristics and price for Ratibida columnifera. ${ }^{\mathrm{Z}}$

Means (SD) Comparison

Component

Single color oval petal lovers Price conscious bicolor petal lovers Knowledgeable marbled petal lovers $F, P$ value

$\frac{\text { Native plant knowledge }}{{ }^{\mathrm{z}} \text { Different letters within a row indicate significant differences of means at } P<0.05 \text {. }}$

Table 7. Cluster proportions including principal component analysis and part-worth utility values derived from responses to a survey designed to elucidate consumer preference of floral characteristics and price for Ratibida columnifera. ${ }^{\mathrm{z}}$

\begin{tabular}{|c|c|c|c|c|}
\hline Variable & \multicolumn{3}{|c|}{ Mean (SD) } & $P$ value \\
\hline$\overline{\text { Age }}$ & $36.73(9.57) \mathrm{b}$ & $39.41(10.88) \mathrm{a}$ & $36.76(36.76) b$ & $0.0003^{*}$ \\
\hline Gender & $1.39(0.49) \mathrm{a}$ & $1.39(0.49) \mathrm{a}$ & $1.40(0.49) \mathrm{a}$ & 0.9910 \\
\hline Ethnicity (\% non-White) & $0.50(0.50) b$ & $0.62(0.48) \mathrm{a}$ & $0.47(0.50) b$ & $<0.0001^{*}$ \\
\hline Education & $4.59(1.15) \mathrm{ab}$ & 4.39 (1.19) b & $4.67(1.22) \mathrm{a}$ & $0.0042 *$ \\
\hline Income (USD \$, 000) & $56.2(39.10) \mathrm{a}$ & $52.5(35.60) \mathrm{a}$ & $51.1(38.40) \mathrm{a}$ & 0.3155 \\
\hline Native knowledge & $0.04(1.00) \mathrm{ab}$ & $-0.09(0.96) \mathrm{b}$ & $0.20(0.94) \mathrm{a}$ & $0.0003 *$ \\
\hline Number of purchase locations & $1.69(0.93) \mathrm{a}$ & $1.77(0.93) \mathrm{a}$ & $1.65(0.95) \mathrm{a}$ & 0.2354 \\
\hline Number of plant types purchased & $2.42(1.46) \mathrm{ab}$ & $2.68(1.78) \mathrm{a}$ & $2.37(1.66) \mathrm{b}$ & $0.0298 *$ \\
\hline \multicolumn{5}{|l|}{ Petal number relative importance } \\
\hline$<10$ & $-0.10(0.25) \mathrm{a}$ & $-0.18(0.29) \mathrm{b}$ & $-0.06(0.22) \mathrm{a}$ & $<0.0001^{*}$ \\
\hline \multicolumn{5}{|l|}{ Petal color relative importance } \\
\hline Yellow & $0.30(0.51) \mathrm{a}$ & $-0.58(0.52) \mathrm{c}$ & $-0.02(0.36) \mathrm{b}$ & $<0.0001^{*}$ \\
\hline \multicolumn{5}{|l|}{ Petal shape relative importance } \\
\hline Circular & $0.11(0.30) \mathrm{a}$ & $0.09(0.31) \mathrm{a}$ & $0.01(0.29) \mathrm{b}$ & $<0.0001^{*}$ \\
\hline Lobed & $-0.06(0.27) \mathrm{ab}$ & $-0.12(0.33) b$ & $-0.01(0.26) \mathrm{a}$ & $<0.0001^{*}$ \\
\hline Notched & $-0.06(0.32) b$ & $0.01(0.29) \mathrm{a}$ & $-0.02(0.27) \mathrm{ab}$ & $0.0225^{*}$ \\
\hline Oval & $0.013(0.27) \mathrm{a}$ & $0.03(0.29) \mathrm{a}$ & $0.02(0.28) \mathrm{a}$ & 0.8669 \\
\hline \multicolumn{5}{|l|}{ Price relative importance } \\
\hline$\$ 10.00$ & $0.11(0.32) b$ & $0.46(0.52) \mathrm{a}$ & $-0.04(0.28) \mathrm{c}$ & $<0.0001^{*}$ \\
\hline$\$ 15.00$ & $-0.01(0.24) \mathrm{a}$ & $0.01(0.25) \mathrm{a}$ & $0.00(0.21) \mathrm{a}$ & 0.6201 \\
\hline$\$ 20.00$ & $-0.10(0.29) b$ & $-0.47(0.52) \mathrm{c}$ & $0.04(0.28) \mathrm{a}$ & $<0.0001^{*}$ \\
\hline
\end{tabular}


knowledge of native plants of the three clusters. Gen X consists of 44 million people who tend to value money, possessions, and the shopping experience more than older generations (Behe et al., 2016). These Gen X trends were reflected in our data for the price conscious bicolor petal lovers, both in their price and store type preferences. This group purchased mainly from brickand-mortar storefronts and used print catalogs and the Internet the least.

The single color oval petal lovers and knowledgeable marbled petal lovers both are heavily weighted toward the Gen Y population. This generation is said to be the most ethnically and culturally diverse age cohort in America today (Behe et al., 2016). The data from our survey did not reflect that sentiment. Both of these groups were very similar in distribution of ethnicity. These groups achieved higher degree educations than their Gen X counterparts. The single color oval petal lovers resided in more suburban regions, whereas the knowledgeable marbled petal lovers resided in more rural locations. Gen Y individuals are often referred to as digital natives, meaning they have always had access to the Internet (Behe et al., 2016). This may explain the more frequent Internet sales seen in the two Gen Y groups.

Variance and risk. In probability theory and statistics, variance is a measure of how far a set of numbers is spread out. It is one of several descriptors of a probability distribution describing how far the numbers lie from the mean (expected value). The goal of this study was to elucidate consumer preferences on observed $R$. columnifera traits, which will in turn reduce risk to the plant breeders as far as return on investment for years of developing a marketable plant product. To illustrate the concept of variance, it is useful to consider an example from the field of finance. Understanding the concept of variance along with three typical asset classes - money market, bonds, stocks - can aid in building a financial portfolio for many. Money market investments are very safe; they almost never go in the red, but they also do not pay high returns. Stocks are on the opposite end of the spectrum, frequently going back and forth between red and black from year to year, but, over longer periods of time, they usually pay higher premiums. Bonds are somewhere in the middle, safer than a stock, but riskier than a money market with their average returns reflecting that risk.

Variance within samples in research studies such as this also can be correlated to risk, as indicated previously. Sometimes there may not be statistically different means between treatment combinations, but the variance can be larger or smaller than other treatment combinations. You can determine the variance by observing the standard deviation alongside means. Variance can be both a positive or negative aspect in that a larger variance generally means larger risk, higher reward potential, and more variability in the results. For instance, a researcher or plant breeder attempting to obtain the best performing genetics for their cultivation program might choose the treatment that includes lower and higher extremes in certain plant attributes in hopes of achieving that higher level of performance. On the other hand, a lower variance may infer less risk, a more dependable reward, or less variability in results. A production greenhouse grower might choose this option in aims of producing a uniform crop and reducing the risk of having unsaleable outliers in their crop. This idea applies to decisions in marketing $R$. columnifera in the sense that we can make more or less risky decisions depending on what market segment we are considering.

Hypothetical bias. The treatment combinations of $R$. columnifera in our survey do not exist currently. Therefore, our survey was ex ante in design, meaning it is a forecast used to guide a decision about what to do in the future because the particular good does not exist yet (Loomis, 2014). This is opposed to ex post, where choices are based on actual revealed preferences rather than forecasts. Thus, although it is appropriate for researchers to elucidate preference on yet-to-bedeveloped goods, hypothetical bias can pose issues when ascertaining if the participant's real-world purchasing decisions will indeed reflect the survey findings. Hypothetical bias is when there is a disconnect between actual cash willingness to pay, and stated willingness to pay; quite often it is an overstatement of willingness to pay (Loomis, 2014). As it relates to our results, that means that it is a likely possibility that consumers will actually purchase 1-gallon containers of $R$. columnifera for less than the $\$ 10$ preference. Hypothetical bias can be minimized with ex ante survey design approaches, such as consequentiality, insisting on honesty, explaining hypothetical bias to respondents, and reducing social desirability (Loomis, 2014). It can also be minimized with ex post approaches, such as data screening, market calibration, and uncertainty recoding. There is no universal agreement on the best method to correct for hypothetical bias, and incorporating several approaches may better capture the true willingness to pay (Loomis, 2014).

\section{Conclusions}

This survey has provided valuable results with regard to decisions on what direction to take for $R$. columnifera breeding selections. This research objective is important because a great deal of time, energy, and resources are put into cultivar development programs. It would be logical to consider developing cultivars with attributes that follow consumers' preferred trends to ensure that a product is developed that resonates with consumers.

Results from this survey provide insights regarding consumer preferences for $R$. columnifera in the following ways. We examined a combination of petal color, petal number, petal shape, and price preference based on part-worth utilities for $R$. columnifera. Consistent with previous literature, we found that petal color was the most important attribute (Behe et al., 1999; Mason et al., 1998). Price was the next most important attribute, followed by petal shape and petal number. This order of importance is seen in previous literature as well (Behe et al., 2001; Grygorczyk et al., 2016). Consumers preferred $R$. columnifera with partial (bicolor) or complete red coloration over other options, lower prices, more petals, and entire circular or oval petals. If these results were to be implemented into a breeding program, it is suggested that petal color be a main focus, followed by petal shape and petal number with regard to floral characteristics. Future research could include additional variation in tints, tones, or shades of red and bicolor patterns. There is a distinct lack of literature on consumer preferences for petal shape; therefore, additional research on petal shape could be useful. Floral characteristics alone are not the only important driving factors in decision making with regard to ornamental plants. Consumers have shown preference and aversion to differing plant sizes and growth habits (Baidu-Forson et al., 1997; Behe et al., 2005). In R. columnifera, conjoint analysis could be performed on different foliage characteristics, plant size, and plant habit as well. Implementing improvements into $R$. columnifera selection that follow the trends of this survey would aid in creation of a product with improved market potential over the species type.

\section{Literature Cited}

Baidu-Forson, J., B.R. Ntare, and F. Waliyar. 1997. Utilizing conjoint analysis to design modern crop varieties: Empirical example for groundnut. Niger. Agr. Econ. 16(3):219-226, https:// doi.org/10.1111/j.1574-0862.1997.tb00456.x.

Behe, B.K., P. Huddleston, and L. Sage. 2016. Age cohort influences brand recognition, awareness, and likelihood to buy vegetable and herb transplants. HortScience 51(2):145-151, https://doi.org/10.21273/HORTSCI.51.2.145.

Behe, B.K., B.L. Campbell, H. Khachatryan, C.R. Hall, J.H. Dennis, P.T. Huddleston, and R. Fernandez. 2014. Incorporating eye tracking technology and conjoint analysis to better understand the green industry consumer. HortScience 49(12):1550-1557, https://doi org/10.21273/HORTSCI.49.12.1550.

Behe, B.K., B.L. Campbell, C.R. Hall, H. Khachatryan, J.H. Dennis, and C. Yue. 2013. Consumer preferences for local and sustainable plant production characteristics. HortScience 48(2):200-208, https:// doi.org/10.21273/HORTSCI.48.2.200.

Behe, B., J. Hardy, S. Barton, J. Brooker, T. Fernandez, C. Hall, J. Hicks, R. Hinson, P. Knight, R. McNiel, and T. Page. 2005. Landscape plant material, size, and design sophistication increase perceived home value. J. Environ. Hort. 23(3):127-133, https://doi. org/10.24266/0738-2898-23.3.127.

Behe, B., R. Nelson, S. Barton, C. Hall, C.D. Safley, and S. Turner. 1999. Consumer preferences for geranium flower color, leaf variegation, and price. HortScience 34(4):740-742, https://doi. org/10.21273/HORTSCI.34.4.740.

Behe, B.K., P.B. Redman, and J.M. Dole. 1997. Consumers prefer red poinsettia cultivars. HortTechnology 7(4):438-441, https://doi.org/ 10.21273/HORTTECH.7.4.438

Berghage, R.D. and D.J. Wolnick. 2000. Consumer color preference in New Guinea impatiens. HortTechnology 10(1):206-208, https://doi.org/ 10.21273/HORTTECH.10.1.206. 
Breidert, C., M. Hahsler, and T. Reutterer. 2006. A review of methods for measuring willingnessto-pay. Innovative Marketing 2(4):8-32.

Brzuszek, R.F., R.L. Harkess, and S.J. Mulley. 2007. Landscape architects' use of native plants in the southeastern United States. HortTechnology 17(1):78-81, https://doi.org/ 10.21273/HORTTECH.17.1.78.

Brzuszek, R.F. and R.L. Harkess. 2009. Green industry survey of native plant marketing in the southeastern United States. HortTechnology 19(1):168-172, https://doi.org/10.21273/HORTSCI.19.1.168.

Burghardt, K.T., D.W. Tallamy, and W.G. Shriver. 2009. Impact of native plants on bird and butterfly biodiversity in suburban landscapes. Conserv. Biol. 23(1):219-224, https:// doi.org/10.1111/j.1523-1739.2008.01076.x.

Burghardt, K.T., D.W. Tallamy, C. Philips, and K.J. Shropshire. 2010. Non-native plants reduce abundance, richness, and host specialization in lepidopteran communities. Ecosphere 1(5):1-22, https://doi.org/10.1890/ES10-00032.1.

Chang, J.B., J.L. Lusk, and F.B. Norwood. 2009. How closely do hypothetical surveys and laboratory experiments predict field behavior? Amer. J. Agr. Econ. 91(2):518-534, https://doi. org/10.1111/j.1467-8276.2008.01242.x.

Curtis, K.R. and M.W. Cowee. 2007. Native plant characteristics appeal to consumers in Nevada. Univ. Nevada Coop. Ext. Fact Sheet-07-17, Reno, NV. p. 1-4.

Difallah, D., E. Filatova, and P. Ipeirotis. 2018. Demographics and dynamics of mechanical turk workers. p. 135-143. Y. Chang, and Z. Chenxiang (eds.). Proc. of the Eleventh ACM International Conf. on Web Search and Data Mining, Assoc. for Computing Machinery, New York, NY, https://doi.org/10.1145/3159652.3159661.

Grygorczyk, A., S. Mhlanga, and I. Lesschaeve. 2016. The most valuable player may not be on the winning team: Uncovering consumer tolerance for color shades in roses. Food Qual. Prefer. 47:23-28, https://doi.org/10.1016/j. foodqual.2015.04.012.

Helfand, G.E., J.S. Park, J.I. Nassauer, and S. Kosek. 2006. The economics of native plants in residential landscape designs. Landsc. Urban Plan. 78(3):229-240, https://doi.org/10.1016/j. landurbplan.2005.08.001.

Kauth, P.J. and H.E. Pérez. 2011. Industry survey of the native wildflower market in Florida. HortTechnology 21(6):779-788, https://doi.org/ 10.21273/HORTTECH.21.6.779.

Khachatryan, H., A.W. Hodges, C.R. Hall, and M.A. Palma. 2020. Production and marketing practices and trade flows in the United States green industry, 2018. J. Environ. Hort. 38(3):73-79, https:// doi.org/10.24266/0738-2898-33.3.125.

Knuth, M., B.K. Behe, C.R. Hall, P. Huddleston, and R.T. Fernandez. 2018. Consumer perceptions of landscape plant production water sources and uses in the landscape during perceived and real drought. HortTechnology 28(1):85-93, https://doi.org/10.21273/HORTTECH03893-17.

Knuth, M.J., B.K. Behe, P.T. Huddleston, C.R. Hall, R.T. Fernandez, and H. Khachatryan. 2020. Water conserving message influences purchasing decision of consumers. Water 12(12):3487, https://doi.org/10.3390/w12123487.

Kuhfeld, W.F. 2010. Marketing research methods in SAS. SAS Institute Incorporated.

Mason, S.C., T.W. Starman, R.D. Lineberger, and B.K. Behe. 2008. Consumer preferences for price, color harmony, and care information of container gardens. HortScience 43(2):380-384, https://doi.org/10.21273/HORTSCI.43.2.380.

Morandin, L.A. and C. Kremen. 2013. Bee preference for native versus exotic plants in restored agricultural hedgerows. Restor. Ecol. 21(1):26-32, https://doi.org/10.1111/j.1526-100X.2012.00876.x.

Roots and Rhizomes. 2020. Ratibida red midget. Roots and Rhizomes, Randolph, WI. 30 Sept.
2020. <https://www.rootsrhizomes.com/product/ $884 / 174>$.

U.S. Census Bureau. 2020. Demographic analysis. 5 Feb. 2021. <https://data.census.gov>.

U.S. Department of Agriculture/National Agricultural Statistics Service. 2017. Census of horticultural specialties. Census of Agriculture, U.S. Dept. Agr., Washington, DC. 25 July 2020. <https:// www.nass.usda.gov/Publications/AgCensus/2017/ Full_Report/Volume_1,_Chapter_1_US/ > .

U.S. Department of Agriculture/National Agricultural Statistics Service. 2021. Floriculture crops summary. Census of Agriculture, U.S. Dept. of Agric., Washington, DC. Accessed 4 Nov. 2021. < https://usda.library.cornell.edu/concern/ publications $/ 0$ p0966899? locale $=$ en $>$.

U.S. Department of Agriculture, Natural Resources Conservation Service. 2006. Plants profile for Ratibida columnifera (Upright Prairie Coneflower). 14 Jan. 2021. <https://plants.usda.gov/ core/profile? symbol=RACO3 $>$.

Whitinger, D., P. Cohen, and J. Feinson. 2021. National Gardening Survey. Natl. Gardening Assn. 5 Nov. 2021. <www.gardenresearch. com $>$.

Wilde, H.D., K.J. Gandhi, and G. Colson. 2015. State of the science and challenges of breeding landscape plants with ecological function. Hort. Res. 2:14069, https://doi.org/10.1038/hortres.2014.69.

Wollaeger, H.M., K.L. Getter, and B.K. Behe. 2015. Consumer preferences for traditional, neonicotinoid-free, bee-friendly, or biological control pest management practices on floriculture crops. HortScience 50(5):721-732, https:// doi.org/10.21273/HORTSCI.50.5.721.

Zadegan, Y.R., B.K. Behe, and R. Gough. 2008. Consumer preferences for native plants in Montana residential landscapes and perceptions for naturalistic designs. J. Environ. Hort. 26(2):109-114, https:// doi.org/10.24266/0738-2898-26.2.109. 